\title{
A Comparison between Post-Operative Analgesia after Intrathecal Injection of Nalbuphine versus Fentanyl as an Adjuvent to Bupivacaine after Cesarean Section
} Azza Youssef Ibrahim, Kareem Youssef Kamal, Hany Magdy Fahim, Ahmed Nasser Ahmed

Department of Anesthesiology, I.C.U and Pain Management, Faculty of Medicine, Ain Shams University

*Corresponding author: Ahmed Nasser Ahmed, E-Mail: ahmednasser_91 @ hotmail.com, Mobile: 01282220006

\begin{abstract}
Background: one of the primary aims of anesthesia is to alleviate the patient's pain and agony, by permitting the performance of surgical procedures without any discomfort. Relief of postoperative pain has gained real importance in recent years considering the central, peripheral and immunological stress response to tissue injury. Any expertise acquired in this field should be extended into the postoperative period, which is the period of severe, intolerable pain requiring attention. So there is a need for extended analgesia without any side effects to achieve this goal. The use of opioids in intrathecal or epidural anesthesia has become popular to optimize postoperative analgesia. However, opioid-induced side effects, such as respiratory depression, nausea, vomiting, urinary retention and pruritus, limit their use. Aim of the Work: the purpose of this study was to assess the postoperative analgesic requirements and the spinally mediated analgesic effects of intrathecal nalbuphine as an adjunct to intrathecal bupivacaine after cesarean section in comparison to intrathecal bupivacaine plus fentanyl. Patients and Methods: eighty female patients came to Demerdash Hospital for cesarean delivery, they were randomly allocated into two equal groups (40 patients) group $\mathrm{F}$ and group N. Group F: Bupivacaine-Fentanyl: Patients received an intrathecal injection of $2 \mathrm{ml}$ of $0.5 \%$ heavy (hyperbaric) bupivacaine plus $0.5 \mathrm{ml}(25 \mu \mathrm{g})$ fentanyl. Group N: Bupivacaine-Nalbuphine: Patients received an intrathecal injection of $2 \mathrm{ml}$ of $0.5 \%$ heavy (hyperbaric) bupivacaine plus $0.5 \mathrm{ml}(0.8 \mathrm{mg})$ Nalbuphine. Results: the addition of a small dose of nalbuphine or fentanyl to bupivacaine in spinal anesthesia moderately prolonged the time of postoperative analgesia, while the duration of analgesia was more prolonged and the adverse effects were minimal with the group of nalbuphine, our result shows no significant difference, but shows significant difference in the More rapid onset of sensory block with Fentanyl than with Naluphine, more rapid Regression time to S1 dermatome with Fentanyl than with Naluphine, the duration of motor block is shorter with Fentanyl than with Naluphine, patients receive rescue analgesia 6 h postoperatively is fewer with Nalpuphine than Fentanyl. Conclusion: more rapid onset of motor block in fentanyl group than in nalbuphine group, more rapid onset of sensory block with Fentanyl than with Naluphine, more rapid regression time to S1 dermatome with Fentanyl than with Naluphine.
\end{abstract}

Keywords: Bupivacaine, Fentany, intrathecal, ACTH, PDPH, Intra-thecal

\section{INTRODUCTION}

Spinal anesthesia is the preferred mean for cesarean section, being simple to perform, economical and produces rapid onset of anesthesia and complete muscle relaxation. It carries high efficiency, involves less drug doses, minimal neonatal depression, awake mother and lesser incidences of aspiration pneumonitis. However, it also produces a fixed duration of anesthesia, postdural puncture headache, hypotension and lesser control of block height ${ }^{(1)}$. Bupivacaine an amide type of local anesthetic; has high potency, slow onset (5-8 minutes) and long duration of action (1.5-2 hours). For cesarean section intrathecal dose of hyperbaric bupivacaine is 12 to $10.8 \mathrm{mg}$. Cesarean delivery requires traction of peritoneum and handling of intraperitoneal organs, resulting in intraoperative visceral pain. With higher doses of hyperbaric bupivacaine, incidence of intraoperative visceral pain associated with higher blocks is reduced ${ }^{(2)}$. Opiods have been a choice in regional (intrathecal and epidural routes) anesthesia to improve the antinociceptive effect of local anesthetics. nalbuphine and fentanyl are being used intrathecally together with local anesthetics in cesarean section. Potentiating the effect of intrathecal local anesthetics by addition of intrathecal opiods for intra-abdominal surgeries is known. In this study by addition of nalbuphine and fentanyl we tried to minimize the dose of bupivacaine, thereby reducing the side effects caused by higher doses of intrathecal bupivacaine in cesarean section ${ }^{(3)}$.

\section{AIM OF THE WORK}

The purpose of this study is to compare the post-operative analgesic effect of intrathecal nalbuphine as an adjuvant to bupivacaine during cesarean delivery and intrathecal fentanyl as an adjuvant to bupivacaine during cesarean delivery. 


\section{PATIENTS AND METHODS}

After approval of Ethical Committee in our faculty and obtaining written informed consent the study was done. Eighty adult female patients presented to Ain-Shams University Obstetric Hospital for cesarean delivery were enrolled in this study. Inclusion criteria: Eighty adult female patients aged between 20 till 35 years. ASA physical status ASA I \& ASA II presented with normal coagulation profile, weight range between 60 to $100 \mathrm{~kg}$, height 160 to $180 \mathrm{~cm}$ and duration of surgery in between 40 minutes to 80 minutes. Exclusion criteria: The exclusion criteria for this study include: Patient refusal, Infection at site of the injection, Any coagulopathy disorder or receiving any anticoagulant drugs, Any preexisting neurological disease, Uncooperative patients, Cardiac or respiratory system failure, known history of allergy to Bubivacaine and any of the study drugs, Failed spinal anesthesia.

\section{RESULTS}

In our study, the postoperative analgesic requirements and the spinally mediated analgesic effects of bupivacaine (hyperbaric) $0.5 \%$ in combination with fentanyl $(25 \mu \mathrm{g})$ or nalbuphine $(0.8 \mathrm{mg})$ in patients undergoing elective cesarean section were observed and recorded. In our study, although the duration of the postoperative analgesia is more prolonged with Nalbuphine group than with fentanyl group, the result was insignificant. In regards to the onset of sensory block, the onset of sensory block is more rapid with Fentanyl than with Naluphine. This difference was found to be highly significant with $P=0.0008$. In regards to the Regression time to $\mathrm{S} 1$ dermatome. The regression time to $\mathrm{S} 1$ dermatomeis more rapid with Fentanyl than with Naluphine. This difference was found to highly significant with $P=0.0007$. In regards to the Duration of motor. The duration of motor block is shorter with Fentanyl than with Naluphine. This difference was found to highly significant with $P=0.0002$. Eighteen patients received rescue analgesia in Fentanyl within $6 \mathrm{~h}$ postoperatively, whereas seven patients received in Naluphine which was found to be highly significant. In relation to the postoperative side effects, hypotention were recorded in the two studied groups and statistically no significant difference was found between Naluphine and Fentanyl.
Table (1): Demographic data and duration of surgery of the two studied groups.

\begin{tabular}{|l|c|c|c|}
\hline \multicolumn{1}{|c|}{ Characteristics } & $\begin{array}{c}\text { Nalbuphine } \\
(\mathbf{n}=\mathbf{4 0})\end{array}$ & $\begin{array}{c}\text { Fentanyl } \\
(\mathbf{n = 4 0})\end{array}$ & p value \\
\hline Age $(\mathrm{yrs})$ & $26.97 \pm 5.40$ & $26.33 \pm 6.08$ & $0.671(\mathrm{NS})$ \\
\hline Height $(\mathrm{cm})$ & $170.30 \pm 6.94$ & $168.97 \pm 5.22$ & $0.404(\mathrm{NS})$ \\
\hline Weight $(\mathrm{kg})$ & $81.53 \pm 9.85$ & $78.83 \pm 8.26$ & $0.255(\mathrm{NS})$ \\
\hline $\begin{array}{l}\text { Duration of surgery } \\
\text { (min.) }\end{array}$ & $57.17 \pm 6.82$ & $57.00 \pm 8.19$ & $0.898(\mathrm{NS})$ \\
\hline
\end{tabular}

Data are expressed as means \pm standard deviation. $N S=p>$ $0.05=$ not significant.

Table (2): Mean $\mathrm{SPO}_{2}(\%)$ of the two studied groups.

\begin{tabular}{|l|c|c|c|}
\hline Time in minutes & $\begin{array}{c}\text { Nalbuphine } \\
(\mathbf{n}=\mathbf{4 0})\end{array}$ & $\begin{array}{c}\text { Fentanyl } \\
(\mathbf{n}=\mathbf{4 0})\end{array}$ & P value \\
\hline Baseline & 97.9 & 98.3 & $0.675(\mathrm{NS})$ \\
\hline $\mathbf{1 5}$ minutes & 98 & 98.4 & $0.664(\mathrm{NS})$ \\
\hline $\mathbf{3 0}$ minutes & 99.1 & 99 & $0.767(\mathrm{NS})$ \\
\hline $\mathbf{4 5}$ minutes & 99.3 & 99.2 & $0.791(\mathrm{NS})$ \\
\hline $\mathbf{6 0}$ minutes & 99.4 & 99.3 & $0.610(\mathrm{NS})$ \\
\hline $\mathbf{7 5}$ minutes & 99.5 & 99.4 & $0.710(\mathrm{NS})$ \\
\hline $\mathbf{9 0}$ minutes & 99.1 & 99.2 & $0.771(\mathrm{NS})$ \\
\hline $\mathbf{1 0 5}$ minutes & 99 & 99.1 & $0.870(\mathrm{NS})$ \\
\hline $\mathbf{1 2 0}$ minutes & 99.5 & 99.4 & $0.775(\mathrm{NS})$ \\
\hline $\mathbf{3}$ hrs & 99.3 & 99.3 & $0.900(\mathrm{NS})$ \\
\hline $\mathbf{4}$ hrs & 99.4 & 99.4 & $0.900(\mathrm{NS})$ \\
\hline $\mathbf{5}$ hrs & 99.4 & 99.3 & $0.790(\mathrm{NS})$ \\
\hline
\end{tabular}

Data are expressed as means \pm standard deviation. $\quad \mathrm{NS}=\mathrm{p}>$ $0.05=$ not significant.

Table (3): Mean heart rate (beat/min.) of the two studied groups.

\begin{tabular}{|c|c|c|c|}
\hline $\begin{array}{l}\text { Time in } \\
\text { minutes }\end{array}$ & $\begin{array}{c}\text { Nalbuphine }(\mathrm{n}= \\
40)\end{array}$ & $\begin{array}{c}\text { Fentanyl }(n= \\
40)\end{array}$ & $P$ value \\
\hline Baseline & $85.93 \pm 8.23$ & $87.67 \pm 7.59$ & $0.475(\mathrm{NS})$ \\
\hline 15 minutes & $83.70 \pm 9.13$ & $88.57 \pm 10.73$ & $0.064(\mathrm{NS})$ \\
\hline 30 minutes & $83.53 \pm 8.87$ & $88.07 \pm 9.92$ & $0.067(\mathrm{NS})$ \\
\hline 45 minutes & $84.20 \pm 8.29$ & $86.63 \pm 9.38$ & $0.291(\mathrm{NS})$ \\
\hline 60 minutes & $83.47 \pm 7.43$ & $86.23 \pm 9.36$ & $0.210(\mathrm{NS})$ \\
\hline 75 minutes & $83.50 \pm 7.61$ & $85.23 \pm 8.55$ & $0.410(\mathrm{NS})$ \\
\hline 90 minutes & $83.67 \pm 6.70$ & $85.93 \pm 8.94$ & $0.271(\mathrm{NS})$ \\
\hline 105 minutes & $83.97 \pm 6.99$ & $84.30 \pm 8.59$ & $0.870(\mathrm{NS})$ \\
\hline 120 minutes & $83.80 \pm 7.23$ & $83.23 \pm 8.05$ & $0.775(\mathrm{NS})$ \\
\hline $3 \mathrm{hrs}$ & $83.27 \pm 7.47$ & $83.03 \pm 6.85$ & $0.900(\mathrm{NS})$ \\
\hline $4 \mathrm{hrs}$ & $82.97 \pm 7.38$ & $82.38 \pm 6.71$ & $0.753(\mathrm{NS})$ \\
\hline 5 hrs & $82.25 \pm 6.19$ & $82.79 \pm 5.42$ & $0.790(\mathrm{NS})$ \\
\hline $6 \mathrm{hrs}$ & $86.25 \pm 5.68$ & $83.75 \pm 5.35$ & $0.511(\mathrm{NS})$ \\
\hline
\end{tabular}

Data are expressed as means \pm standard deviation. $\quad \mathrm{NS}=\mathrm{p}>$ $0.05=$ not significant. 
Table (4): Mean systolic blood pressure $(\mathrm{mmHg})$ of the two studied groups.

\begin{tabular}{|l|c|c|c|}
\hline Time in minutes & $\begin{array}{c}\text { Nalbuphine } \\
(\mathbf{n}=\mathbf{4 0})\end{array}$ & $\begin{array}{c}\text { Fentanyl } \\
(\mathbf{n}=\mathbf{4 0})\end{array}$ & P value \\
\hline Baseline & $112.17 \pm 6.25$ & $109.67 \pm 8.50$ & $0.200(\mathrm{NS})$ \\
\hline $\mathbf{1 5}$ minutes & $99.17 \pm 9.75$ & $100.83 \pm 11.15$ & $0.540(\mathrm{NS})$ \\
\hline $\mathbf{3 0}$ minutes & $99.67 \pm 5.24$ & $100.33 \pm 8.60$ & $0.718(\mathrm{NS})$ \\
\hline $\mathbf{4 5}$ minutes & $99.67 \pm 4.14$ & $101.17 \pm 6.78$ & $0.305(\mathrm{NS})$ \\
\hline $\mathbf{6 0}$ minutes & $102.50 \pm 3.41$ & $103.33 \pm 5.77$ & $0.499(\mathrm{NS})$ \\
\hline $\mathbf{7 5}$ minutes & $105.0 \pm 4.55$ & $106.17 \pm 7.62$ & $0.474(\mathrm{NS})$ \\
\hline $\mathbf{9 0}$ minutes & $107.33 \pm 3.65$ & $108.0 \pm 8.16$ & $0.684(\mathrm{NS})$ \\
\hline $\mathbf{1 0 5}$ minutes & $111.33 \pm 5.86$ & $110.83 \pm 7.32$ & $0.771(\mathrm{NS})$ \\
\hline $\mathbf{1 2 0}$ minutes & $113.0 \pm 3.85$ & $114.0 \pm 7.47$ & $0.517(\mathrm{NS})$ \\
\hline $\mathbf{3}$ hrs & $116.33 \pm 4.14$ & $114.50 \pm 6.21$ & $0.184(\mathrm{NS})$ \\
\hline $\mathbf{4}$ hrs & $120.23 \pm 5.95$ & $119.07 \pm 6.99$ & $0.463(\mathrm{NS})$ \\
\hline $\mathbf{5} \mathbf{~ h r s}$ & $121.06 \pm 5.68$ & $119.67 \pm 5.68$ & $0.202(\mathrm{NS})$ \\
\hline $\mathbf{6 ~ h r s}$ & $126.43 \pm 5.69$ & $125.0 \pm 5.00$ & $0.293(\mathrm{NS})$ \\
\hline
\end{tabular}

Table (5): Mean diastolic blood pressure ( $\mathrm{mmHg}$ ) of the two studied groups.

\begin{tabular}{|l|c|c|c|}
\hline Time in minutes & $\begin{array}{c}\text { Nalbuphine } \\
(\mathbf{n = 4 0})\end{array}$ & $\begin{array}{c}\text { Fentanyl } \\
(\mathbf{f}=\mathbf{4 0})\end{array}$ & p value \\
\hline Baseline & $70.83 \pm 5.10$ & $68.50 \pm 6.04$ & $0.111(\mathrm{NS})$ \\
\hline $\mathbf{1 5}$ minutes & $63.50 \pm 6.84$ & $61.33 \pm 6.69$ & $0.220(\mathrm{NS})$ \\
\hline $\mathbf{3 0}$ minutes & $60.83 \pm 5.43$ & $62.33 \pm 5.04$ & $0.272(\mathrm{NS})$ \\
\hline $\mathbf{4 5}$ minutes & $63.50 \pm 4.76$ & $64.50 \pm 5.92$ & $0.474(\mathrm{NS})$ \\
\hline $\mathbf{6 0}$ minutes & $64.56 \pm 5.51$ & $65.33 \pm 4.90$ & $0.356(\mathrm{NS})$ \\
\hline $\mathbf{7 5}$ minutes & $65.53 \pm 4.79$ & $67.17 \pm 4.87$ & $0.159(\mathrm{NS})$ \\
\hline $\mathbf{9 0}$ minutes & $67.83 \pm 2.52$ & $66.33 \pm 4.54$ & $0.119(\mathrm{NS})$ \\
\hline $\mathbf{1 0 5}$ minutes & $68.67 \pm 3.70$ & $69.50 \pm 5.31$ & $0.483(\mathrm{NS})$ \\
\hline $\mathbf{1 2 0}$ minutes & $70.50 \pm 4.42$ & $72.00 \pm 6.38$ & $0.294(\mathrm{NS})$ \\
\hline $\mathbf{3 ~ h r s}$ & $71.67 \pm 4.79$ & $70.67 \pm 4.69$ & $0.417(\mathrm{NS})$ \\
\hline $\mathbf{4}$ hrs & $76.01 \pm 6.52$ & $74.93 \pm 6.18$ & $0.156(\mathrm{NS})$ \\
\hline $\mathbf{5}$ hrs & $77.81 \pm 7.06$ & $74.67 \pm 7.19$ & $0.229(\mathrm{NS})$ \\
\hline $\mathbf{6} \mathbf{~ h r s}$ & $77.93 \pm 4.56$ & $78.15 \pm 3.57$ & $0.401(\mathrm{NS})$ \\
\hline
\end{tabular}

Table (6): Sensory block, motor block and duration of analgesia of the two studied groups.

\begin{tabular}{|c|c|c|c|c|}
\hline \multicolumn{2}{|r|}{$\begin{array}{c}\text { Block characteristics and } \\
\text { postoperative analgesia }\end{array}$} & $\begin{array}{c}\text { Group F } \\
(n=40)\end{array}$ & $\frac{\text { Group N }}{(n=40)}$ & $p$ value \\
\hline \multicolumn{5}{|c|}{ Sensory block } \\
\hline 1 & Onset of sensory block & $2.50 \pm 0.76$ & $4.63 \pm 1.19$ & $0.0008^{* * 4}$ \\
\hline 2 & Peak sensory block level & $\mathrm{T} 4$ (T1-T7) & $\mathrm{T} 4$ (T1-T7) & \\
\hline 3 & $\begin{array}{l}\text { Time to peak sensory block } \\
(\mathrm{min})\end{array}$ & $7.40 \pm 2.58$ & $8.27 \pm 2.91$ & 0.225 \\
\hline 4 & $\begin{array}{l}\text { Regression time to S1 } \\
\text { dermatome (min.) }\end{array}$ & $120.88 \pm 7.81$ & $136.31 \pm 6.15$ & $0.0007 * *$ \\
\hline \multicolumn{5}{|c|}{ Motor block } \\
\hline 5 & Onset of motor block & $5.53 \pm 0.23$ & $5.70 \pm 0.17$ & $0.008^{* * *}$ \\
\hline 6 & $\begin{array}{l}\text { Maximum motor block to } \\
\text { MBS }\end{array}$ & 1.3 & 1.4 & 0.529 \\
\hline 7 & Duration of motor block & $148.13 \pm 23.09$ & $220 \pm 34.59$ & $0.0002^{* *}$ \\
\hline \multicolumn{5}{|c|}{ Analgesia } \\
\hline 8 & Duration of analgesia & $\begin{array}{c}150.83 \pm \\
30.96\end{array}$ & $\begin{array}{c}160.33 \pm \\
14.02\end{array}$ & 0.096 \\
\hline 9 & $\begin{array}{c}\text { post operativerescue } \\
\text { analgesia }\end{array}$ & 18 & 7 & $.004 * *$ \\
\hline 10 & $\begin{array}{l}\text { Time to first analgesic } \\
\text { requirement (min) }\end{array}$ & $159.33 \pm 0.23$ & $160.58 \pm 2.58$ & 0.584 \\
\hline
\end{tabular}

Data are expressed as mean $\pm \mathrm{SD}$, NS $(\mathrm{P}>0.05)$. $\mathrm{SD}=$ Standard deviation, $\quad \mathrm{BF}=$ Bupivacaine-fentanyl, $\quad \mathrm{BN}=$ Bupivacaine nalbuphine, VAS=Visual analog scale, NS=Non significant., $* *=$ Highly significant result
Table (7): Modified Bromage score.

\begin{tabular}{|c|l|}
\hline Score & \multicolumn{1}{|c|}{ Criteria } \\
\hline 1 & Complete block (unable to move feet or knees) \\
\hline 2 & Almost complete block (able to move feet only) \\
\hline 3 & Partial block (just able to move knees) \\
\hline 4 & $\begin{array}{l}\text { Detectable weakness of hip flexion while supine } \\
\text { full flexion of knees) }\end{array}$ \\
\hline 5 & $\begin{array}{l}\text { No detectable weakness of hip flexion while } \\
\text { supine }\end{array}$ \\
\hline 6 & Able to perform partial knee bend \\
\hline
\end{tabular}

Table (8): Adverse effects in the two studied groups.

\begin{tabular}{|l|c|c|c|}
\hline Characteristics & $\begin{array}{c}\text { Nalbuphine } \\
(\mathbf{n}=\mathbf{4 0})\end{array}$ & $\begin{array}{c}\text { Fentanyl } \\
(\mathbf{n}=\mathbf{4 0})\end{array}$ & P value \\
\hline Nause \& vomiting & $2(6.7 \%)$ & $3(10 \%)$ & 0.301 \\
\hline Pruritis & $0(0 \%)$ & $1(3.3 \%)$ & 0.313 \\
\hline Shivering & $1(3.3 \%)$ & $2(6.7 \%)$ & 0.554 \\
\hline
\end{tabular}

Data are expressed as means \pm standard deviation or number $(\%) . \mathrm{NS}=\mathrm{p}>0.05=$ not significant.

\section{DISCUSSION}

Recent trends of obstetric anesthesia show increased popularity of regional anesthesia among obstetric anesthetists. General anesthesia is associated with higher mortality rate in comparison to regional anesthesia. However, regional anesthesia is not without risk. Deaths in regional anesthesia are primarily related to excessive high regional blocks and toxicity of local anesthetics. Reduction in doses and improvement in technique to avoid higher block levels and heightened awareness to the toxicity of local anesthetics have contributed to the reduction of complications related to regional anesthesia ${ }^{(4)}$. These days $0.5 \%$ heavy bupivacaine is used commonly for spinal and epidural anesthesia. It was decided to combine it with intrathecal fentanyl to provide adequate depth of anesthesia with lesser doses of bupivacaine ${ }^{(5)}$. Intrathecal opioids cause segmental analgesia by binding to opioid receptors in the dorsal horn of the spinal cord. They significantly prolong the duration of analgesia without affecting motor or autonomic nervous function. They may, however, be associated with a number of dosedependent side effects. The most serious side effect of intrathecal opioids is respiratory depression, while the most common side effect is pruritus. Other undesirable side effects include nausea, vomiting, urine retention, and sedation (6). Intrathecal administration of local anesthetic and 
opioid combinations is based on the clinical observation that their combination limits the regression of the sensory block seen with local anaesthetics alone and improves the quality of dynamic pain relief ${ }^{(6)}$. In regards to the onset of motor block, the onset of motor block is more rapid with fentanyl than nalbuphine, and this significant difference in the onset of motor block may be explained by the high lipid solubility and rapid tissue uptake of Fentanyl more than Nalbuphine, and this needs further investigations. Also in our study, No statistically significant difference in the Heart rate and SPO2 between the two studied groups, neither bradycardia nor desaturation of the oxygen were recorded. There was no significant difference with regard to: Peak sensory block level, Time to peak sensory block, Maximum motor block, Duration of analgesia, Time to first analgesic requirement. A study conducted by Obara et al. ${ }^{(7)}$, who explored the effect of intrathecal fentanyl added to hyperbaric bupivacaine on the characteristics of subarachnoid block in patients undergoing cesarean section. The results of their study showed that the maximum level of sensory blockade was significantly higher in the fentanyl group as compared with the control group (this group received bupivicaine and normal saline). Also, the required amount of intraoperative analgesics was smaller in the fentanyl group, although the difference was not significant. They concluded that addition of intrathecal fentanyl to hyperbaric bupivacaine in parturients undergoing cesarean section improved quality of anesthesia without producing significant side effects. The results of this study also agree with Chavada and colleagues ${ }^{(8)}$ who conducted a study comparing intrathecal fentanyl and sufentanil added to heavy bupivacaine for postoperative analgesia for patients undergoing vaginal hysterectomy. Their study concluded that the addition of fentanyl $(25 \mu \mathrm{g})$ and sufentanil $(5 \mu \mathrm{g})$ intrathecally provide improved postoperative analgesia and hemodynamic stability. We found the first study which used intrathecal nalbuphine was conducted by Culebras et al. (9) which injected $(0.8 \mathrm{mg})$ nalbuphine with bupivacain in comparison to morphine with bupivacaine in cesarean section and their study concluded that intrathecal nalbuphine $0.8 \mathrm{mg}$ provides good intraoperative and early postoperative analgesia without side effects. With respect to the neurotoxicity of intrathecal nalbuphine, Rawal et al. ${ }^{(10)}$ showed in a sheep model using histopathological methods, that intrathecal nalbuphine was not neurotoxic. Even large doses (15-24 mg) of intrathecal nalbuphine were not associated with histopathological changes of the spinal cord. In the same study, however, the smallest dose of intrathecal sufentanil was associated with inflammatory changes, axonal swelling, and shrunken neurons. With the largest dose of sufentanil, there were signs of meningitis and arachnoiditis. Regarding the appropriate dose of intrathecal nalbuphine, the study conducted by Culebras et al. ${ }^{(9)}$ recommend the dose of $0.8 \mathrm{mg}$ Nalbuphine to be injected intrathecally as they found that this is the best dose to improve the intraoperative analgesia and prolonges early postoperative analgesia, without increasing the risk of side effects. As they compared between the dose of $(0.2 \mathrm{mg})$ and the dose $(0.8 \mathrm{mg})$ and the dose $(1.6$ $\mathrm{mg})$ of nalbuphine and the dose $(0.2 \mathrm{mg})$ of morphine. However, the study conducted by Akhilesh Kumar Tiwari et al. ${ }^{(1 I)}$ injected $(0.4 \mathrm{mg})$ Nalbuphine and found that dose provides good intraoperative and early postoperative analgesia with minimal adverse effects with hemodynamic stability. The results of our study agree with Tiwari et al. ${ }^{(11)}$ which conducts a study comparing intrathecal Bupivacaine and a Combination of Nalbuphine and Bupivacaine for Subarachnoid Block. Their study concluded that: Nalbuphine hydrochloride $(400 \mu \mathrm{g})$ significantly prolongs the duration of sensory blockade and postoperative analgesia without any side effect or complication when introduced intrathecally along with hyperbaric bupivacaine. Although, they injected $0.4 \mathrm{mg}$ nalbuphine and we injected $(0.8 \mathrm{mg})$ but they agree with our study that nalbuphine has no side effects or complications when introduced intrathecally along with hyperbaric bupivacaine. The study of Culebraset al. ${ }^{(9)}$ results agree with our study results, this study compared between advantages of Intrathecal nalbuphine and Intrathecal morphine, after cesarean delivery: And evaluated postoperative analgesia and adverse effects. Also this study agreed with our study, as it found that the best dose of Nalbuphine to be injected is $0.8-1.6 \mathrm{mg}$. This study suggests that intrathecal nalbuphine $0.8 \mathrm{mg}$ provides good intraoperative and early postoperative analgesia without side effects. However, only morphine provides long-lasting analgesia. Small doses of 
intrathecal nalbuphine $(0.4 \mathrm{mg})$ or $(0.8 \mathrm{mg}) \mathrm{mg}$ produce fewer adverse effects, such as pruritus and postoperative nausea and vomiting, compared with intrathecal morphine. This may allow earlier discharge of patients from the recovery room. Culebras et al. ${ }^{(9)}$; conducted that, There was no maternal or newborn respiratory depression. Neonatal conditions (Apgar scores and umbilical vein and artery blood gas values) were similar for all groups, as it compared multiple doses of nalbuphine $(0.2 \mathrm{mg}),(0.8 \mathrm{mg})$ and $(1.6 \mathrm{mg})$ with $(0.2 \mathrm{mg})$ morphine.

\section{CONCLUSION}

More rapid onset of motor block in fentanyl group than in nalbuphine group. More rapid onset of sensory block with Fentanyl than with Naluphine. More rapid Regression time to S1 dermatomewith Fentanyl than with Naluphine. The duration of motor block is shorter with Fentanyl than with Naluphine. Patients receive Rescue analgesia $6 \mathrm{~h}$ postoperatively is fewer than with Nalpuphine than Fentanyl There was no significant difference with regard to: Peak sensory block level, Time to peak sensory block, Maximum motor block, Duration of analgesia, Time to first analgesic requirement.

\section{CONFLICTS OF INTEREST}

There are no conflicts of interest.

\section{REFERENCES}

1- Venkata HG, Pasupuleti S, Pabba UG, Porika S, Talari G (2015): A randomized controlled prospective study comparing a low dose bupivacaine and fentanyl mixture to a conventional dose of hyperbaric bupivacaine for cesarean section. Saudi journal of anaesthesia, 9(2): 122.

2- Bogra J, Arora N, Srivastava P (2005): Synergistic effect of intrathecal fentanyl and bupivacaine in spinal anesthesia for cesarean section. BMC anesthesiology, 5(1): 5 .

3- Benhamou D, Thorin D, Brichant JF, Dailland P, Milon D, Schneider M (1998): Intrathecal clonidine and fentanyl with hyperbaric bupivacaine improves analgesia during cesarean section. Anesthesia \& Analgesia, 87:609-613.
4- Courtney MA, Bader AM, Hartwell B, Hauch M, Grennan MJ, Datta S (1992): Perioperative analgesia with subarachnoid administration. Regional Anesthesia. 17:274-8.

5- Kang FC, Tsai YC, Chang PJ, Chen TY (1998): Subarachnoid fentanyl with dilute small dose bupivacaine for cesarean section. Acta Anaesthesiol Sin.,36:207214.

6- Prakash S, Gupta A, Deshpande A, Kale KS (2006): The effect of intrathecal midazolam $2.5 \mathrm{mg}$ with bupivacaine on postoperative pain relief in patients undergoing orthopaedic surgery. Journal of Anaesthesia and Clinical Pharmacology, 24 (2): 189-192.

7- Obara M, Sawamura S, Satoh Y, Chinzei M, Sekiyama H, Tamai $H$ (2003): The effect of intrathecal nalbuphine added to hyperbaric bupivacaine for caesarean section. Masui., 52: 378-382.

8- Chavada H, Mehta PJ, Vyas AH (2009): A Comparative Study of Intrathecal nalbuphine and morphine with Bupivacaine Heavy for Postoperative Analgesia. The Internet Journal of Anesthesiology, 20: 2-8

9- Culebras X, Gaggero G, Zatloukal Jet al. (2000): Advantages of intrathecal nalbuphine, compared with intrathecal morphine, after cesarean delivery: an evaluation of post operative analgesia and adverse effects. Anesth Analg., 91:601605.

10- Rawal N, Nuutinen L, Raj PP, Lovering SL, Gobuty AH, Hargardine Jet al. (1991): Behavioral and histopathologic effects following intrathecal administration of butorphanol, sufentanil, and nalbuphine in sheep. Anesthesiology, 75:1025-34.

11- Tiwari AK, Tomar GS, Agrawal J (2013): Intrathecal bupivacaine in comparison with a combination of nalbuphine and bupivacaine for subarachnoid block: a randomised prospective double blind clinical study.Am J Ther., 6:592-95. 